\title{
Congenital posterior urethral diverticulum in an infant with Robinow syndrome - diagnostic difficulties
}

\author{
Stanisław Warchol ${ }^{1}$, Przemyslaw Bombinski ${ }^{2}$ Jacek Skiendzielewski $^{3}$ and Teresa Dudek-Warchol ${ }^{1}$ \\ ${ }^{1}$ Department of Pediatric Surgery and Urology, Medical University of Warsaw, Poland \\ ${ }^{2}$ Department of Pediatric Radiology, Medical University of Warsaw, Poland \\ ${ }^{3}$ Department of Pediatric Cardiology, Medical University of Warsaw, Poland
}

\begin{abstract}
Congenital posterior urethral diverticulum (PUD) is a rare congenital anomaly. Proper diagnosis and treatment in such cases still is challenging. More common are acquired diverticula of the posterior urethra, which mostly follow surgical repair of imperforate anus. We report a case of a large, congenital PUD which was diagnosed in a 3-month old boy with very rare genetic disorder Robinow syndrome, as a result of bladder catheterization difficulties before cardiac surgery. There was no previous history of voiding problems or urinary tract infections. External genital abnormalities are typical clinical findings in children with Robinow syndrome, as it was in presented patient. Imaging studies showed large PUD. The described case shows than even large PUD may be primarily asymptomatic and its diagnosis is somewhat difficult.
\end{abstract}

\section{Introduction}

Congenital posterior urethral diverticulum (PUD) is an extremely rare urogenital anomaly. There is a lack of information about this entity and only a few reports are available in the literature [1-5]. More common encountered are acquired cases of diverticulum of the posterior urethra, which mostly follow surgical reconstruction of imperforate anus [6-8]. Also anterior urethral diverticula are found to be more common $[9,10]$.

\section{Case report}

A 3-month old male (46XY) with Robinow syndrome accompanied by multiple congenital anomalies, including urogenital system (micropenis together with webbed penis, hypoplastic scrotum and bilateral intraabdominal testes) and cardiac system (Tetralogy of Fallot with extreme right ventricluar outflow tract obstruction) underwent cardiac surgery. During and after operation no urine output was noted, despite the introduced preoperatively by the anesthesiologist Foley catheter into the bladder. Urine leak only along the catheter was

noted. There was no previous history of micturition problems as well as urinary tract infection. The pediatric urologist was asked for advice.

Ultrasound examination (US) showed distended bladder and retrovesically localized encapsulated fluid collection (Figure 1a, Figure 1b).Repeated bladder catheterization was unsuccessful to obtain urine and puncture set for suprapubic catheterization Cystofix ${ }^{\bullet}$ (B. Braun Melsungen AG, Germany) was introduced. Contrast study through the suprapubic catheter revealed the presence of large diverticulum of the posterior urethra (Figure 2), while computed tomographic urography normal upper urinary tract (Figure 3). Because of the diverticulum anatomical configuration, the catheter introduced through the urethra easily reached the lumen of the diverticulum insted of bladder (Figure 4).
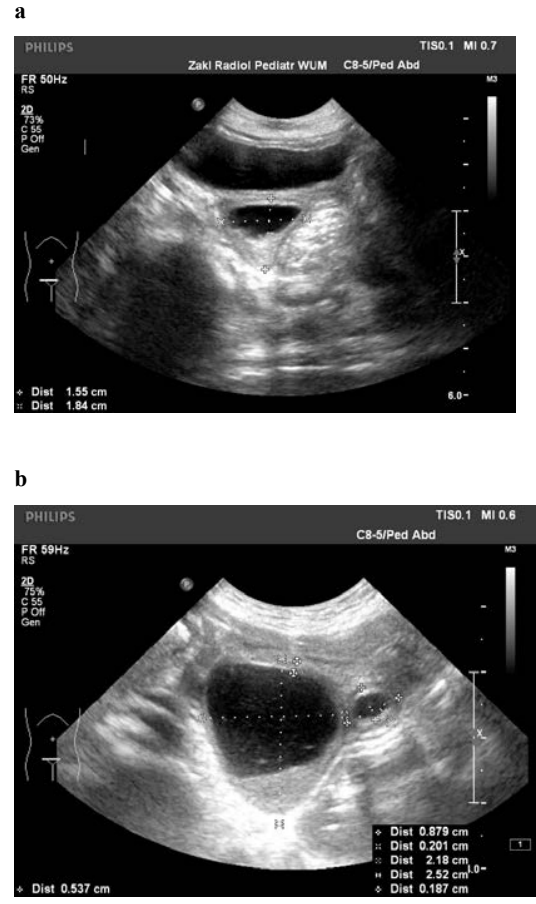

Figure 1. a and b. US before insertion of suprapubic catheter: distended bladder and retrovesically localized, encapsulated fluid collection.

Correspondence to: Stanislaw Warchol PhD, MD, Department of Pediatric Surgery and Urology, Medical University of Warsaw, 02-91 Zwirki and Wigury street, Warsaw, Poland, Tel. (48) 606189852 / ( 48 22) 3179746, E-mail: swarchol@poczta.onet.pl

Key words: posterior urethral diverticulum, congenital urethral anomaly, robinow syndrome

Received: April 02, 2017; Accepted: April 24, 2017; Published: April 27, 2017 


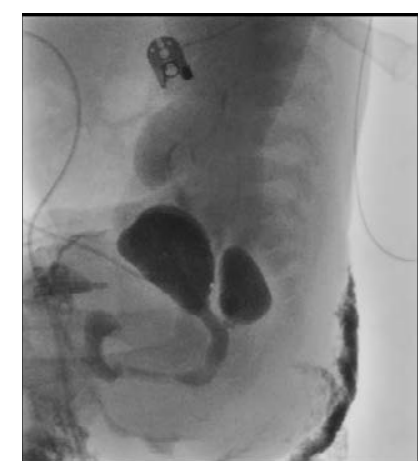

Figure 2. Contrast study through suprapubic catheter: large diverticulum of the posterior urethra.

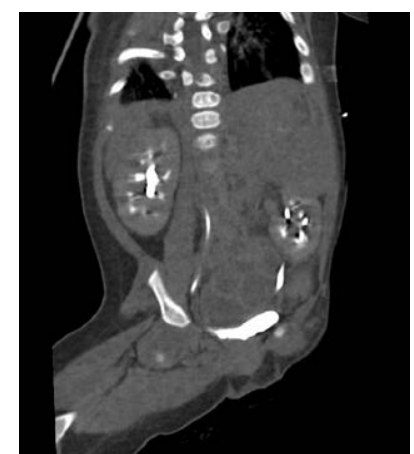

Figure 3. Computed tomographic urography: normal upper urinary tract.

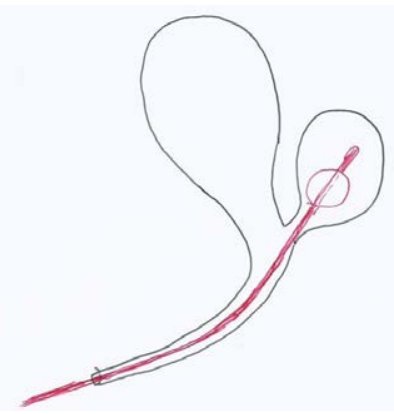

Figure 4. Schematic drawing of anatomical configuration of posterior urethral diverticulum.

Cystofix ${ }^{\bullet}$ was removed after 2 weeks and the boy voided normally, however, control US showed persisting, encapsulated fluid collection retrovesically, representing diverticulum (Figure 5). At the age of 13 months before the second step of cardiac surgery Cystofix ${ }^{\circledR}$ was used to avoid previous encountered problems with bladder catheterization. Meanwhile two episodes of urinary tract infection were noted.

\section{Discussion}

Posterior urethral diverticulum may be asymptomatic or pose variable symptoms such as micturition difficulties, urgency, infections and secondary calculi formations $[2,4,5]$. In presented case PUD was completely asymptomatic before its recognition and diagnosis was made as a result of bladder catheterization problems. The anatomical configuration of the diverticulum was responsible for above.

Ultrasound and voiding cystourethrography are usually initial diagnostic modalities of choice and adequate to establish diagnosis of PUD $[2,3,5]$. However, a giant PUD may cause diagnostic difficulties

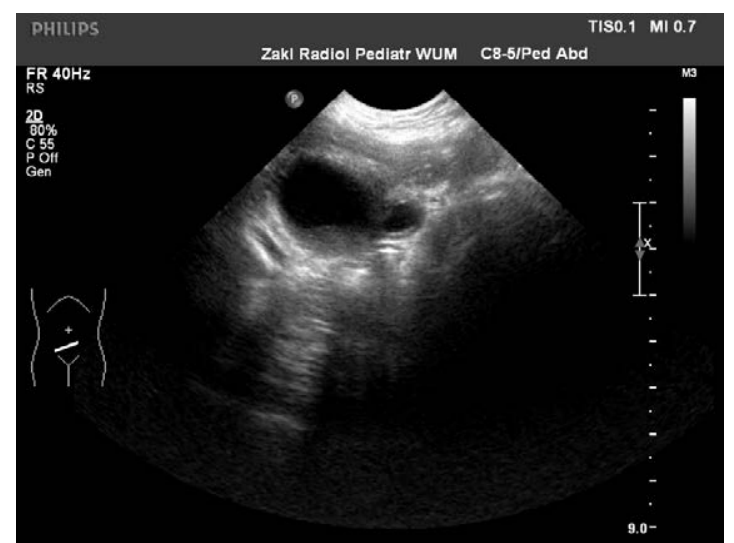

Figure 5. US: persisting, encapsulated fluid collection retrovesically, representing diverticulm.

and additional images, such as MRI may be required for proper assessment [4].

The method of PUD treatment depends on the size of the diverticulum and the presence of symptoms. Small and asymptomatic diverticula, generally may not require any treatment $[1,2]$. Management of symptomatic lesions, however, often is a surgical challenge. In majority of the diverticula transurethral unroofing is most appropriate. The larger require open excision and eventually urethral reconstruction $[1,2,5]$. Minimally invasive surgical approach to treat PUD in children has been described recently [5].

Robinow syndrome is an extremely rare genetic disorder, characterized by skeleton findings (short stature, limb shortening predominantly of the upper limb, brachydactyly), dysmorphic facial features, external genital abnormalities (in males micropenis, webbed penis, hypoplastic scrotum, cryptorchidism). Coexisting cardiac defects are a major cause of morbidity and mortality [11,12].

To our knowledge the presented case with its unique clinical course is the first described PUD diagnosed because of bladder catheterization problems. Our observation also shows than even large PUD may be primarily asymptomatic and its diagnosis somewhat difficult.

In our patient no further urological procedures were applied because of general bad condition of the child, which limited treatment options.

\section{References}

1. Esposito G, Savanelli A, Tenore A, Tamburrini O, Palescandolo P, et al. (1986) Congenital giant diverticulum of the posterior urethra in a 4-year-old boy. $Z$ Kinderchir 41: 244-245. [Crossref]

2. Mousavi S, Mehrsai A, Nikoobakht M, Abedi AR, Salem S, et al. (2006) A giant congenital posterior urethral diverticulum associated with renal dysplasia. Urol $J 3$ : 247-249. [Crossref]

3. Jana M, Gupta AK, Prasad KR, Goel S, Tambade VD, et al. (2011) Pictorial essay: Congenital anomalies of male urethra in children. Indian J Radiol Imaging 21: 38-45. [Crossref]

4. Kundum PR, Gupta AK, Thottom PV, Jana M (2010) Technical note: dynamic MRI in a complicated giant posterior urethral diverticulum. Indian J Radiol Imaging 20: 300-303. [Crossref]

5. Alsowayan O, Almodhen F, Alshammari A (2015) Minimally invasive surgical approach to treat posterior urethral diverticulum. Urol Ann 7: 273-276. [Crossref]

6. Hong AR, Acuña MF, Peņa A, Chaves L, Rodriguez G (2002) Urologic injuries associated with repair of anorectal malformations in male patients. $J$ Pediatr Surg 37 339-344. [Crossref] 
7. Alam S, Lawal TA, Pena A, Sheldon C, Levitt MA (2011) Acquired posterior urethral diverticulum following surgery for anorectal malformations. J Pediatr Surg 46: 12311235. [Crossref]

8. Pandey V, Gangopadhyay AN, Gupta DK, Sharma SP, Kumar V (2014) Management of anorectal malformation without ligation of fistula: an approach preventing posterior urethral diverticula. J Pediatr Urol 10:1149-1152. [Crossref]

9. Gupta DK, Srinivas M (2000) Congenital anterior urethral diverticulum in children. Pediatr Surg Int 16: 565-568. [Crossref]
10. Rawat J, Khan TR, Singh S, Maletha M, Kureel S (2009) Congenital anterior urethral valves and diverticula: diagnosis and management in six cases. Afr J Paediatr Surg 6: 102-105. [Crossref]

11. Patton MA, Afzal AR (2002) Robinow syndrome. J Med Genet 39: 305-310. [Crossref]

12. Roifman M, Brunner H, Lohr J, Mazzeu J, Chitayat D (2015) Autosomal dominan Robinow syndrome. In: Pagon RA, Adam MP, Ardinger HH, Wallace SE, et al. (edtr). GeneReviewsŪ [Internet]. Seattle (WA): University of Washington, Seattle; 19932017. 2015 Jan 8 [updated 2015 Jul 30].

Copyright: (C2017 Warchol S. This is an open-access article distributed under the terms of the Creative Commons Attribution License, which permits unrestricted use, distribution, and reproduction in any medium, provided the original author and source are credited. 